\title{
LOW BACK PAIN AMONG FEMALE NURSES IN YEMEN
}

\author{
KHALED GHILAN ${ }^{1}$, ABDULLA AL-TAIAR ${ }^{2}$, NUHA AL YOUSFI', \\ RANIA AL ZUBAIDI ${ }^{1}$, IMAN AWADH ${ }^{1}$, and ZAHER AL-OBEYED ${ }^{1}$ \\ ${ }^{1}$ Sana'a University, Sana'a, Yemen \\ Faculty of Medicine and Health Sciences \\ ${ }^{2}$ Kuwait University, Kuwait, Kuwait \\ Faculty of Medicine
}

\begin{abstract}
:
Objectives: This study aimed to investigate the prevalence of Low Back Pain (LBP) among female nursing staff and explore the potential risk factors associated with LBP. Methods: An analytical cross-sectional study was conducted on randomly selected female nurses using payroll as a sampling frame in all public hospitals in Sana'a City, Yemen. Data was collected through face-to-face interview using a structured, pre-coded questionnaire that was available in Arabic and English. Weight and height of the nurses were measured using weight and height scales and body mass index was calculated. Multiple logistic regression was used to identify the factors associated with LBP. Results: Out of 696 female nurses selected, 687 $(98.7 \%)$ responded. The life-time, the 12-month and one-week prevalence rates of LBP among female nurses were 512 (74.5\%; 95\% CI: 71.1-77.7\%), 411 (59.8\%; 95\% CI: 56.0-63.5\%) and 249 (36.2\%; 95\% CI: 32.6-39.9\%), respectively. The prevalence was significantly lower in Indian nurses compared to other nurses. Three out of every 10 nurses with LBP had sick leave because of LBP in the last 12 months. Factors that showed significant association with LBP among nursing staff in the multivariate analysis were age, nationality, menstrual disorders and stress level at work. Conclusion: LBP is common among female nurses in Yemen. The role of menstrual disorders in developing LBP among female nurses seems to be important. Although sharing the same working conditions, Indian nurses were less likely to report LBP, which highlight the importance of cultural differences in willingness to report LBP.
\end{abstract}

Key words:

Low back pain, Nurses, Prevalence, Risk factors, Yemen

\section{INTRODUCTION}

Low Back Pain (LBP) is a major public health problem with over $80 \%$ of the world population reporting LBP at some point in their life [1]. It causes a considerable economic burden presenting a major cause of medical expenses, absenteeism, and disability [2]. In Australia, for example, there were 3.6 million medical consultations and 2.9 million prescriptions for back pain during 1993/1994 [3]; while in the United States, expenditures incurred by individuals with back pain reached 90.7 billion U.S. dollars in 1998 [4]. The direct costs of LBP in UK, USA, and
Australia represent between 0.19 and 0.42 of Gross Domestic Product, which is between $1.65 \%$ and $3.22 \%$ of the total health expenditure [5].

A higher prevalence of LBP has often been shown among healthcare workers compared to other professionals. Nurses, who tolerate the physical effort of handling patients, hospitals' equipment and the work related emotional stress on a daily basis, are one of the occupational groups that are most frequently affected by LBP. During the professional career of a nurse, a life-time LBP prevalence of $80 \%$ has been reported [6-8], while most studies

Received: August 8, 2012. Accepted: May 23, 2013

Corresponding author: K. Ghilan, Department of Community Medicine, Faculty of Medicine and Health Sciences, Sana'a University, Box: 1440 Sana'a, Yemen (e-mail:kghilan@yahoo.co.uk). 
reported a 12-month prevalence of 33-86\% [9]. Although the prevalence of LBP and its related risk factors among nursing staff has been investigated in industrialized countries, there is paucity of data in poor settings, particularly in Middle East. This cross-sectional study aimed to investigate the prevalence of LBP among female nurses working in major public hospitals in Yemen and to investigate the potential risk factors associated with LBP among the nursing staff.

\section{METHODS}

It is estimated that over 12000 nurses and 4000 midwives work in Yemen in more than 237 public and private hospitals. Most of them are Yemeni citizens, while others come mainly from India. The study was conducted in the four major public hospitals in Sana'a city with approximately 1832 nurses. In order to select a representative sample of female nurses in the study hospitals, we used the payroll lists in all study hospitals as a sampling frame. Nurses were selected from the payroll list using a simple random sample with randomly generated numbers by Microsoft Excel Function, after exclusion of non-Arabic non-English speakers. Selected nurses were then approached during their work were invited to participate in the study. Second and third attempts were made to interview those nurses who were absent. The number of nurses selected in each hospital was proportional to the number of nurses working in that hospital.

Data was collected through face-to-face interview using a structured, pre-coded questionnaire. The questionnaire was available in Arabic and English versions according to the participant's language. The questionnaire comprised data on socio-demographic data, experience of LBP, and possible risk factors for LBP. Intensity of the pain was assessed using a 10-point horizontal visual analogue scale (VAS) in which point number one indicates absence of LBP while point number 10 indicates worst pain $[10,11]$. Similarly, horizontal 10-point VAS describing the stress level during work [12], and work satisfaction [13] were used. Height and weight of each participating nurse were measured using a height scale and a weight scale that was calibrated after every 10 measurements. Weight was measured after participant has removed heavy clothing and was recorded to nearest $0.1 \mathrm{~kg}$. The data collection tool was pilot tested on twenty participants of whom none was included in the study. One question was removed and few others were reworded after this pilot testing.

The data was entered and analysed by Statistical Package for Social Sciences (SPSS) version 18. Body Mass Index (BMI) was calculated as weight $(\mathrm{kg}) /$ height $^{2}(\mathrm{~m})$. The $95 \%$ confidence interval (CI) for the estimated prevalence of LBP was obtained using exact binomial distribution. Unconditional logistic regression was used to calculate crude and adjusted odds ratios (ORs) and their 95\% CIs to investigate the association between potential risk factors and LBP. Risk factors were categorized into groups such as socio-demographic and work-related factors. Factors that were significant at 0.2 level of significance in the univariate analysis, were considered in the multivariate model. In the final model, only factors significant at 0.05 level of significance were included. Backward and forward stepwise selection was used to check the final model and both approaches selected the same factors which identified by manual selection of variables. Likelihood ratio test was used to identify factors significantly associated with LBP comparing the model with and without the variable. The study was approved at The Faculty of Medicine and Health Sciences, Sana'a University and verbal consent was obtained from each participant after adequate explanation of the nature of the study.

\section{RESULTS}

Three nurses were absent and could not be approached and another six refused to participate in the study. Table 1 shows the socio-demographic characteristics 
Table 1. Socio-demographic characteristics of female nurses in public hospital, Yemen 2010

\begin{tabular}{lc}
\hline \multicolumn{1}{c}{ Characteristics } & $\begin{array}{c}\text { Respondents } \\
(\mathrm{N}=687)\end{array}$ \\
\hline Age (years), M (SD) & $29.4(6.6)$ \\
Marital status [n (\%)] & \\
single & $306(44.5)$ \\
married & $361(52.6)$ \\
divorced & $20(2.9)$ \\
Children* $[\mathrm{n}(\%)]$ & \\
no children & $76(20.0)$ \\
1-3 & $260(68.2)$ \\
$\geq 4$ & $45(11.8)$ \\
Nationality [n (\%)] & \\
Yemeni & $332(48.3)$ \\
Indian & $346(50.4)$ \\
others & $9(1.3)$ \\
Monthly income** $[\mathrm{n}(\%)]$ & \\
$>10000$ & $221(32.2)$ \\
$>47000$ & $214(31.2)$ \\
$>70000$ & $252(36.7)$ \\
\hline
\end{tabular}

* Applicable only to those who have ever married.

** In Yemeni Rials. of the study group. The mean (SD) age was 29.4 (6.6) years and approximately half of the participants were Indian. The life-time, 12-month, and one-week prevalence of LBP among female nursing staff in hospitals in Sana'a city is shown in Table 2. The lifetime prevalence of LBP was $74.5 \%$ (95\% CI: $71.1-$ $77.7 \%$ ) while the 12 -month prevalence was $59.8 \%$ (95\% CI: 56.0-63.5\%). The one-week prevalence was $36.2 \%$ (95\% CI: 32.6-39.9\%); of those, more than half had used medication to treat their LBP. Prevalence of LBP was persistently higher among Yemeni nurses in comparison to Indian nurses. Out of those with LBP in the last 12-month, 139 (29.1\%) missed at least one day of their work because of LBP.

Association between socio-demographic factors and LBP in the last 7 days in the univariate analysis is shown in Table 3. Associations between LBP in the last 7 days and both reproductive factors and work-related factors are shown in Table 4 and Table 5, respectively. Factors that showed significant association with LBP in the last 7 days in the univariate analysis were age, nationality, marital status, number of children, chewing of Qat (the leaves of the shrub Catha edulis, which are chewed like tobacco

Table 2. Prevalence and severity of low back pain among female nurses in public hospitals, Yemen 2010

\begin{tabular}{lcc}
\hline \multicolumn{1}{c}{ Variable } & $\begin{array}{c}\text { Nurses } \\
\mathrm{n}(\%)\end{array}$ & 95\% CI \\
\hline Life-time prevalence $(\mathrm{N}=687)$ & $512(74.5)$ & $71.1-77.7$ \\
12-month prevalence $(\mathrm{N}=687)$ & $411(59.8)$ & $56.0-63.5$ \\
One-week prevalence $(\mathrm{N}=687)$ & $249(36.2)$ & $32.6-39.9$ \\
Medication used for LBP in the last 12 months $(\mathrm{N}=411)$ & $175(42.5)$ & - \\
Sick leave due to LBP in the last 12 months $(\mathrm{N}=411)$ & $114(27.7)$ & - \\
Severity of pain on analogue scale in the last 7 days $(\mathrm{N}=249)$ & & - \\
1-3 & $26(10.4)$ & - \\
$4-6$ & $137(55.0)$ & - \\
$\geq 7$ & $86(34.5)$ & \\
\hline
\end{tabular}

CI - confidence interval. 
for their stimulating effect), BMI, presence of other diseases, irregular menstrual cycle, breast tenderness prior to menstruation, years at work as a nurse, working on day shifts, stress level at work and job satisfaction. In the multivariate analysis, factors that were significantly associated with LBP in the last 7 days were age, nationality, irregular menstrual cycle and stress level at work (Table 6). Obesity lost its statistical significance in the final model. Breast tenderness prior to the menses was significantly associated with LBP in the last 7 days but was dropped due to collinearity with irregular menstrual cycle.

Table 3. Association between low back pain in the last 7 days and socio-demographic characteristics, personal habits and Body Mass Index (BMI) in a univariate analysis

\begin{tabular}{|c|c|c|}
\hline Risk factor & OR $(95 \% \mathrm{CI})$ & $\mathrm{p}$ \\
\hline Age (years) & $1.03(1.01-1.05)$ & 0.010 \\
\hline Nationality & & $<0.001$ \\
\hline Yemeni & 1 (Reference) & \\
\hline Indian & $0.46(0.34-0.63)$ & \\
\hline Marital status & & $<0.001$ \\
\hline single & 1 (Reference) & \\
\hline married & $1.76(1.27-2.44)$ & \\
\hline divorced/widowed & $3.03(1.21-7.56)$ & \\
\hline Children & & 0.010 \\
\hline no children & 1 (Reference) & \\
\hline $1-3$ & $1.92(1.10-3.33)$ & \\
\hline$\geq 4$ & $3.07(1.42-6.62)$ & \\
\hline Monthly income* & & 0.020 \\
\hline$>10000$ & 1 (Reference) & \\
\hline$>47000$ & $0.61(0.40-0.91)$ & \\
\hline$>70000$ & $0.62(0.43-0.89)$ & \\
\hline Smoking status & & 0.220 \\
\hline non-smoker & 1 (Reference) & \\
\hline smoker/ex-smoker & $1.79(0.70-4.56)$ & \\
\hline Chewing qat (yes) & $1.76(1.12-2.79)$ & 0.020 \\
\hline Exercise (yes) & $1.08(0.76-1.52)$ & 0.670 \\
\hline Average sleeping hours & & 0.450 \\
\hline$\leq 5$ & 1 (Reference) & \\
\hline $6-8$ & $0.89(0.52-1.52)$ & \\
\hline$\geq 9$ & $0.61(0.27-1.52)$ & \\
\hline
\end{tabular}


Table 3. Association between low back pain in the last 7 days and socio-demographic characteristics, personal habits and Body Mass Index (BMI) in a univariate analysis - cont.

\begin{tabular}{|c|c|c|}
\hline Risk factor & OR $(95 \% \mathrm{CI})$ & $\mathrm{p}$ \\
\hline BMI & & 0.006 \\
\hline$<18.5$ & 1 (Reference) & \\
\hline $18.5-24.9$ & $0.81(0.47-1.40)$ & \\
\hline $25-29.9$ & $1.16(0.64-2.08)$ & \\
\hline$\geq 30$ & $2.46(1.09-5.54)$ & \\
\hline
\end{tabular}

* In Yemeni Rials.

$\mathrm{OR}$ - odds ratio; CI - confidence interval.

Table 4. Association between low back pain in the last 7 days and presence of other diseases, irregular menstrual cycle and dysmenorrhea in a univariate analysis

\begin{tabular}{lcc}
\hline \multicolumn{1}{c}{ Risk factor } & OR $(95 \%$ CI $)$ & $p$ \\
\hline Presence of other disease (yes) & $1.60(1.07-2.37)$ & \\
Menstrual cycle* & & \\
$\quad$ regular & 1 (Reference) & 0.020 \\
$\quad$ irregular & $2.02(1.28-3.19)$ & 0.002 \\
Breast tenderness prior to the period (yes)* & $1.68(1.18-2.41)$ & 0.004 \\
Breast tenderness during the period (yes)* & $0.99(0.64-1.54)$ & 0.979 \\
Currently taking oral contraceptive (yes) & $1.36(0.77-2.41)$ & 0.289 \\
\hline
\end{tabular}

* This applies to those not pregnant or post menopausal.

Abbreviations as in Table 3.

Table 5. Association between low back pain and work-related factors in a univariate analysis

\begin{tabular}{|c|c|c|}
\hline Risk factor & OR $(95 \% \mathrm{CI})$ & $\mathrm{p}$ \\
\hline Department & & 0.060 \\
\hline surgical wards & 1 (Reference) & \\
\hline medical wards & $0.88(0.56-1.38)$ & \\
\hline paediatric wards & $0.70(0.37-1.30)$ & \\
\hline intensive care units & $0.76(0.44-1.33)$ & \\
\hline outpatient & $1.53(0.90-2.61)$ & \\
\hline obstetrics/gynecology & $1.71(0.98-2.96)$ & \\
\hline emergency & $0.75(0.39-1.46)$ & \\
\hline Period working as a nurse (years) & & $<0.001$ \\
\hline$<5$ & 1 (Reference) & \\
\hline $5-<10$ & $1.12(0.74-1.71)$ & \\
\hline$\geq 10$ & $2.16(1.48-3.14)$ & \\
\hline
\end{tabular}


Table 5. Association between low back pain and work-related factors in a univariate analysis - cont.

\begin{tabular}{|c|c|c|}
\hline Risk factor & OR $(95 \% \mathrm{CI})$ & $\mathrm{p}$ \\
\hline Night shift work (yes) & $0.60(0.44-0.83)$ & 0.002 \\
\hline No. patients dealt per day & & 0.090 \\
\hline$<10$ & 1 (Reference) & \\
\hline $10-<25$ patients & $1.36(0.92-2.02)$ & \\
\hline$\geq 25$ & $1.54(1.04-2.29)$ & \\
\hline Stress level at work* & & $<0.001$ \\
\hline$<5$ & 1 (Reference) & \\
\hline $5-<7$ & $1.02(0.63-1.65)$ & \\
\hline$\geq 7$ & $2.58(1.66-3.99)$ & \\
\hline Job satisfaction level* & & 0.020 \\
\hline$<4$ & 1 (Reference) & \\
\hline $4-<6$ & $0.61(0.40-0.91)$ & \\
\hline$\geq 6$ & $0.62(0.43-0.89)$ & \\
\hline
\end{tabular}

* Self-assessment using Visual Analogue Scale.

Abbreviations as in Table 3.

Table 6. Factors significantly associated with low back pain in the last 7 days in a multivariate analysis

\begin{tabular}{|c|c|c|}
\hline Risk factor & OR $(95 \% \mathrm{CI})$ & $\mathrm{p}$ \\
\hline Age (years) & 1.04 & 0.004 \\
\hline \multicolumn{3}{|l|}{ Nationality } \\
\hline Yemeni & 1 (Reference) & $<0.001$ \\
\hline Indian & $0.50(0.35-0.71)$ & \\
\hline Irregular menstrual cycle (yes) & $1.71(1.05-2.77)$ & 0.031 \\
\hline \multicolumn{3}{|l|}{ Stress level at work* } \\
\hline$<5$ & 1 (Reference) & $<0.001$ \\
\hline $5-<7$ & $0.84(0.50-1.40)$ & \\
\hline$\geq 7$ & $2.04(1.28-3.23)$ & \\
\hline
\end{tabular}

* Self-assessment using Visual Analogue Scale.

Abbreviations as in Table 3.

\section{DISCUSSION}

LBP among nursing staff has attracted attention because of its economic and social burden. We performed an analytical cross-sectional study to assess the prevalence of LBP among nursing staff in Sana'a city, and to explore the potential risk factors associated with LBP. The life-time prevalence of LBP was $74.5 \%$, which is slightly lower than that reported from Taiwan (82\%) [7] or Australia where 79\% of undergraduate nursing students had LBP [14] in their life time. Our estimate of 12-month prevalence of LBP is $60 \%$, which is similar to 
that reported in Thai public hospitals [15] but slightly lower than that reported among female nurses in Nigeria and Ethiopia [16,17] or Japan [18]. The differences in the estimated prevalence of LBP between different settings or within the same setting are common. In Italy, the 12-month prevalence of LBP among nurses varied widely between $33 \%$ and $86 \%$ [9]. Different methodological approaches can be one of the possible reasons as even small differences in methods can influence the resulting prevalence [19]. The cultural differences in the willingness to report LBP as a health problem between different countries. More important are cultural changes in some settings have led to a greater awareness of more minor back symptoms and willingness to report them and thus might be responsible for the increase in the prevalence of LBP over time. In UK, for example, the age and sex standardized prevalence of minor LBP had increased from $36.4 \%$ to $49.1 \%$ over 10 -year period, although the age and sex standardized prevalence of severe LBP (that made it impossible to put on hosiery) fell by $0.7 \%$ [20]. Whether the apparent increase in the prevalence of LBP over time reflects a genuine increase in the occurrence of LBP or is due to the cultural shift in willingness to report LBP or attributable to methodological issues remains the matter of continuous intense debate [19-21].

We have attempted to investigate the factors associated with LBP among female nurses in the last 7 days. As in other studies [22,23], age was significant risk factor for LBP in univariate and multivariate analyses. Another socio-demographic factor that showed striking association with LBP in the univariate and multivariate analyses was nationality of the nurse, with Indian nurses being less likely to report LBP in comparison to other nurses. This further accentuates the role of cultural background in the willingness to report LBP, as both Indian and Yemeni nurses share the same working conditions. Exercising was not significantly associated with LBP in the univariate or multivariate analysis. The association between LBP and practicing exercise among nursing staff remained controversial [24-26]. Obesity was associated with LBP in the univariate analysis but lost statistical significance in the final model. In Japanese nurses, increasing body weight was associated with a 13 -fold increase in the likelihood of LBP affecting their daily activity [18]. Smoking was not reported to be significant risk factor for LBP among nursing staff in other settings [22,26,27]. In our study, only small number of nurses were smokers or exsmokers, which may explain the lack of association between smoking and LBP.

Reproductive symptoms and menstrual disorders were significantly related to LBP in the univariate and multivariate analyses. Nurses with irregular menstrual cycle were twice more likely to have LBP in the last seven days. Similarly, nurses with breast tenderness prior to their period were more likely to report LBP. Similar findings have been reported from Japan and they highlighted the role of menstrual disorders in the development of LBP among Japanese nurses [18]. Nevertheless, cross-sectional studies by their nature do not indicate the direction of this relationship, and thus our findings should be interpreted with caution. Studies that investigated the association between back pain and the use of oral contraceptive in general population have resulted in controversial findings $[28,29]$. Among nursing staff, our findings showed that the current use of oral contraceptive was not significantly related to LBP in the last 7 days.

Although several work-related factors were associated with LBP in the univariate analysis, most of them lost statistical significance in the multivariate analysis. Working in intensive care units or any other particular wards was not significantly associated with LBP, although previous studies have reported extremely high prevalence of LBP among nurses working in intensive care units [30,31]. Night shift work was inversely associated with LBP but this was due to confounding by nationality as most of Indian nurses, who were less likely to report LBP, work in night shifts. Other studies have shown that shift workers are at a higher risk of LBP [32] particularly those who are obese or overweight [33]. The only work-related factor that was 
significantly associated with LBP in the multivariate analysis is the stress level at work.

This is similar to other studies, which reported stress or psychological factors as a major risk factor for LBP among nursing staff $[22,34,35]$. Years at work were not significantly associated with LBP after adjusting for age, although it has been reported to be a significant risk factor for LBP [36] or pain severity and disability [7] in other studies. However, it should be made clear; that we collected data only on a limited number of work-related factors, and thus the association between LBP and other measures of workload, such as frequency of moving heavy weights, remained unknown in our setting.

As in other studies, it is likely that nurses who suffer from severe LBP had abandoned their job, which may have biased the prevalence of LBP downward (healthy worker effect). The other limitation is related to the nature of the cross-sectional studies that does not detect the chronological order of exposure and outcome and thus when the association between stress and LBP, for example, is found it is not clear whether stress has led to LBP or LBP itself has caused stress.

In summary, we have demonstrated that LBP is common among female nurses in Yemen; $60 \%$ had LBP in the last 12 months and approximately three out of every 10 nurses with LBP had sick leave because of LBP. The role of menstrual disorders in developing LBP among female nurses seems to be important. Although sharing the same working conditions, Indian nurses were less likely to report LBP, which highlights the importance of cultural differences in considering LBP as a health problem that is worth reporting.

\section{ACKNOWLEDGMENTS}

We are grateful to all nurses for their cooperation during the collection of data. We are also grateful to Abdullah Al Juhi, Abdulmohsen Al Olaliby, Basheer Al Kamel and Ibrahim Ghaishan for their contribution to this study.

\section{REFERENCES}

11. Walker BF. The prevalence of low back pain: A systematic review of the literature from 1966 to 1998. J Spinal Disord. 2000;13(3): 205-17, http://dx.doi.org/10.1097/00002517200006000-00003.

12. Van Tulder MW, Koes BW, Bouter LM. A cost-of-illness study of back pain in the Netherlands. Pain. 1995;62(2): 233-40, http://dx.doi.org/10.1016/0304-3959(94)00272-G.

13. Mathers C, Penm R. Health system costs of injury, poisoning and musculoskeletal disorders in Australia; 1993-1994. Canberra: University of Sydney and the Australian Institute of Health and Welfare; 1999.

14. Luo X, Pietrobon R, Sun SX, Liu GG, Hey L. Estimates and patterns of direct health care expenditures among individuals with back pain in the United States. Spine. 2004;29(1): 79-86, http://dx.doi.org/10.1097/01. BRS.0000105527.13866.0F.

15. Kent PM, Keating JL. The epidemiology of low back pain in primary care. Chiropr Osteopat. 2005;13:13, http://dx.doi. org/10.1186/1746-1340-13-13.

16. Chiou WK, Wong MK, Lee YH. Epidemiology of low back pain in Chinese nurses. Int J Res Nurs Stud. 1994;31(4): 361-8, http://dx.doi.org/10.1016/0020-7489(94)90076-0.

7. Lin PH, Tsai YA, Chen WC, Huang SF. Prevalence, characteristics, and work-related risk factors of low back pain among hospital nurses in Taiwan: A cross-sectional survey. Int J Occup Med Environ Health. 2012;25(1):41-50, http:// dx.doi.org/10.2478/s13382-012-0008-8.

8. Videman T, Ojajarvi A, Riihimaki H, Troup JD. Low back pain among nurses: A follow-up beginning at entry to the nursing school. Spine. 2005;30(20):2334-41, http://dx.doi. org/10.1097/01.brs.0000182107.14355.ca.

9. Lorusso A, BrunoS,LA'AbbateN. A review oflow back pain and musculoskeletal disorders among Italian nursing personnel. Ind Health. 2007;45(5):637-44, http://dx.doi.org/10.2486/ind health.45.637.

10. Huskisson EC. Measurement of pain. J Rheumatol. 1982;9(5):768-9. 
11. Huskisson EC. Measurement of pain. Lancet. 1974;2(7889):1127-31, $\quad$ http://dx.doi.org/10.1016/S01406736(74)90884-8.

12. Lesage FX, Berjot S. Validity of occupational stress assessment using a visual analogue scale. Occup Med (Lond). 2011;61(6):434-6, http://dx.doi.org/10.1093/occmed/ kqr037.

13. Ugwu AC, Egwu OA, Ochie K, Ewunonu EO, Ovuoba KN, Njoku CO. Incidence of occupational stress among medical radiographers: A population based zonal survey. Niger J Physiol Sci. 2007;22(1-2):123-7.

14. Mitchell T, O'Sullivan PB, Burnett AF, Straker L, Rudd C. Low back pain characteristics from undergraduate student to working nurse in Australia: A cross-sectional survey. Int J Nurs Stud. 2008;45(11):1636-44, http://dx.doi. org/10.1016/ j.jinurstu.2008.03.001.

15. Sopajareeya C, Viwatwongkasem C, Lapvongwatana P, Hong O, Kalampakorn S. Prevalence and risk factors of low back pain among nurses in a Thai public hospital. J Med Assoc Thai. 2009;92 Suppl 7:S93-9.

16. Sikiru L, Hanifa S. Prevalence and risk factors of low back pain among nurses in a typical Nigerian hospital. Afr Health Sci. 2010;10(1):26-30.

17. Sikiru L, Shmaila H. Prevalence and risk factors of low back pain among nurses in Africa: Nigerian and Ethiopian specialized hospitals survey study. East Afr J Public Health. 2009;6(1):22-5, http://dx.doi.org/10.4314/eajph. v6i1.45737.

18. Smith DR, Mihashi M, Adachi Y, Shouyama Y, Mouri F, Ishibashi $\mathrm{N}$, et al. Menstrual disorders and their influence on low back pain among Japanese nurses. Ind Health. 2009;47(3):301-12, http://dx.doi.org/10.2486/indhealth.47.301.

19. Macfarlane GJ, McBeth J, Garrow A, Silman AJ. Life is as much a pain as it ever was. BMJ. 2000;321(7265):897, http:// dx.doi.org/10.1136/bmj.321.7265.897.

20. Palmer KT, Walsh K, Bendall H, Cooper C, Coggon D. Back pain in Britain: comparison of two prevalence surveys at an interval of 10 years. BMJ 2000;320(7249):1577-8, http:// dx.doi.org/10.1136/bmj.320.7249.1577.

21. Croft P. Is life becoming more of a pain? BMJ. 2000;320(7249):1552-3， http://dx.doi.org/10.1136/ bmj.320.7249.1552.

22. Mitchell T, O'Sullivan PB, Smith A, Burnett AF, Straker L, Thornton J, et al. Biopsychosocial factors are associated with low back pain in female nursing students: A cross-sectional study. Int J Nurs Stud. 2009;46(5):678-88, http://dx.doi. org/10.1016/ j.jpnurstu.2008.11.004.

23. Tucer B, Yalcin BM, Ozturk A, Mazicioglu MM, Yilmaz Y, Kaya M. Risk factors for low back pain and its relation with pain related disability and depression in a Turkish sample. Turk Neurosurg. 2009;19(4):327-32.

24. Feng CK, Chen ML, Mao IF. Prevalence of and risk factors for different measures of low back pain among female nursing aides in Taiwanese nursing homes. BMC Musculoskel Disord. 2007;8:52, http://dx.doi.org/10.1186/14712474-8-52.

25. Yip Y. A study of work stress, patient handling activities and the risk of low back pain among nurses in Hong Kong. J Adv Nurs. 2001;36(6):794-804, http://dx.doi.org/10.1046/j.13652648.2001.02037.x.

26. Violante FS, Fiori M, Fiorentini C, Risi A, Garagnani G, Bonfiglioli R, et al. Associations of psychosocial and individual factors with three different categories of back disorder among nursing staff. J Occup Health. 2004;46(2):100-8, http://dx.doi.org/10.1539/joh.46.100.

27. Marena C, Gervino D, Pistorio A, Azzaretti S, Chiesa P, Lodola $\mathrm{L}$, et al. [Epidemiologic study on the prevalence of low back pain in health personnel exposed to manual handling tasks]. G Ital Med Lav Ergon. 1997;19(3):89-95. Italian.

28. Wreje U, Isacsson D, Aberg H. Oral contraceptives and back pain in women in a Swedish community. Int J Epidemiol. 1997;26(1):71-4, http://dx.doi.org/10.1093/ije/26.1.71.

29. Vessey M, Painter R, Mant J. Oral contraception and other factors in relation to back disorders in women: findings 
in a large cohort study. Contraception. 1999;60(6):331-5, http://dx.doi.org/10.1016/S0010-7824(99)00103-1.

30. Sun J, He Z, Wang S. [Prevalence and risk factors of occupational low back pain in ICU nurses]. Chin J Ind Hyg Occup Dis. 2007;25(8):453-5. Chinese.

31. June KJ, Cho SH. Low back pain and work-related factors among nurses in intensive care units. J Clin Nurs. 2011;20 (3-4):479-87, http://dx.doi.org/10.1111/j.13652702.2010.03210.x.

32. Eriksen W, Bruusgaard D, Knardahl S. Work factors as predictors of intense or disabling low back pain; a prospective study of nurses' aides. Occup Environ Med. 2004;61(5): 398404, http://dx.doi.org/10.1136/oem.2003.008482.

33. Zhao I, Bogossian F, Turner C. The effects of shift work and interaction between shift work and overweight/obesity on low back pain in nurses: results from a longitudinal study. J Occup Environ Med. 2012;54(7):820-5, http://dx.doi. org/10.1097/JOM.0b013e3182572e6a.

34. Josephson M, Vingard E. Workplace factors and care seeking for low-back pain among female nursing personnel. MUSIC-Norrtalje Study Group. Scand J Work Environ Health. 1998;24(6):465-72, http://dx.doi.org/10.5271/sjweh.370.

35. Yip VY. New low back pain in nurses: work activities, work stress and sedentary lifestyle. J Adv Nurs. 2004;46(4): 43040, http://dx.doi.org/10.1111/j.1365-2648.2004.03009.x.

36. Byrns G, Reeder G, Jin G, Pachis K. Risk factors for work-related low back pain in registered nurses, and potential obstacles in using mechanical lifting devices. J Occup Environ Hyg. 2004;1(1):11-21, http://dx.doi. org/10.1080/15459620490249992.

This work is available in Open Access model and licensed under a Creative Commons Attribution-NonCommercial 3.0 Poland License - http://creativecommons.org/ licenses/by-nc/3.0/pl/deed.en. 